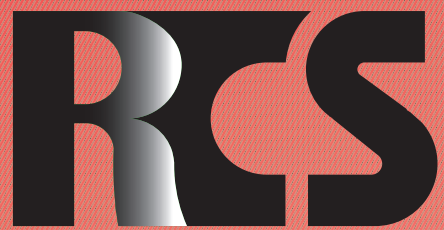

Depósito legal ppi $201502 Z U 4662$

Esta publicación científica en formato digital es continuidad de la revista impresa Depósito Legal: pp $197402 Z U 789$

- ISSN: 1315-9518 • ISSN-E: 2477-9431

Revista de Ciencias Sociales

Universidad del Zulia. Revista de la Facultad de Ciencias Económicas y Sociales Vol. XXVII. No. 2

Abril-Junio 2021

Esta publicación científica en formato digital es continuidad de la revista impresa Depósito Legal: pp $197402 Z$ Z789 ISSN: 1315-9518 


\title{
Masculinidad, migración y pobreza extrema: Mirada retrospectiva de exmigrantes en Hermosillo, Sonora-México*
}

\author{
Romero Plana, Virginia**
}

\section{Resumen}

Este trabajo tiene por objetivo identificar el significado de la responsabilidad como elemento de la identidad masculina configurada en los contextos de pobreza desde la mirada retrospectiva de hombres en situación de calle. Desde un enfoque cualitativo, a través de la técnica de la entrevista semiestructurada se han elaborado cuatro historias de vida de hombres, exmigrantes, que acuden a un albergue para personas sin hogar en Hermosillo, Sonora (México). A partir de los relatos en primera persona se ha analizado que la identidad masculina en los contextos de pobreza parte de dos ejes: a) la responsabilidad de proveer a la familia y b) la libertad adquirida al convertirse en migrante, como estrategia para el desarrollo. Al migrar se crea una desvinculación física y relacional significativa con el contexto de origen y con la familia. Tras las deportaciones o dificultades para cruzar la frontera, esta distancia se transforma en orgullo masculino y vergüenza que no permiten el regreso al hogar ni la petición de ayuda. Se concluye, que es necesaria la inclusión de la mirada de género para entender los significados de la migración, la familia y la responsabilidad masculina en los proyectos de intervención social en contextos de pobreza extrema.

Palabras clave: Pobreza extrema; masculinidad; familia; migración; México.

* Este artículo es uno de los productos de la investigación "Sobrevivir sin lágrimas: relatos de las estadísticas de pobreza", desarrollada entre septiembre de 2018 y agosto de 2019. Este estudio estuvo apoyado por el Programa para el Desarrollo Profesional Docente de México. Agradecimiento enormemente y de corazón a Alfredo, Francisco, Alejandro y Celso por su colaboración. Sus recuerdos y sentires fueron valiosos para la conformación de este artículo.

** Doctora en Estudios Mexicanos, con Especialidad en Antropología de la Pobreza. ProfesoraInvestigadora del Departamento de Trabajo Social en la Universidad de Sonora, México. E-mail: virginia.romero@unison.mx (iD) ORCID: http://orcid.org/0000-0002-9149-0572

Recibido: 2020-12-04 • Aceptado: 2021-02-21 


\title{
Masculinity, migration and extreme poverty: A retrospective look at ex-migrants in Hermosillo, Sonora-Mexico
}

\begin{abstract}
The objective of this work is to identify the meaning of responsibility as an element of the masculine identity configured in the contexts of poverty from the retrospective view of men living on the street. From a qualitative approach, through the semi-structured interview technique, four life stories of men, ex-migrants, who go to a shelter for homeless people in Hermosillo, Sonora (Mexico) have been elaborated. From the first-person accounts, it has been analyzed that male identity in poverty contexts starts from two axes: a) the responsibility to provide for the family and b) the freedom acquired by becoming a migrant, as a strategy for development. Migrating creates a significant physical and relational disconnection with the context of origin and with the family. After deportations or difficulties to cross the border, this distance transforms into masculine pride and shame that do not allow the return home or the request for help. It is concluded that the inclusion of the gender perspective is necessary to understand the meanings of migration, the family and male responsibility in social intervention projects in contexts of extreme poverty.
\end{abstract}

Keywords: Extreme poverty; masculinity; family; migration; Mexico.

\section{Introducción}

Al igual que la línea del bienestar separa a la población en pobres y no pobres, dentro de la primera dimensión se diferencia entre situaciones de pobreza y de pobreza extrema (Hernández, 2010). Este límite radica en la cantidad de carencias sociales que se tengan sin cubrir y en la posibilidad de obtener la canasta básica, según el Consejo Nacional de Evaluación de la Política de Desarrollo Social de México (CONEVAL, 2018).

En México hay aproximadamente 44 millones de personas que viven en situación de pobreza moderada $(35,9 \%$ de la población total), mientras que la pobreza extrema se centra en 9.375 .581 personas, 7,6\% de la población en todo el país (CONEVAL, 2017). En esta situación de precariedad hay dos grupos: Las familias, y las personas en situación de calle. La Secretaría de Desarrollo Social mexicana, bajo la directriz de la Ley General de Desarrollo Social (Cámara de Diputados del H. Congreso de la Nación, 2018), es la responsable de gestionar las ayudas económicas y materiales así como de la inserción de las y los jefes de familia en situaciones de pobreza en los proyectos sociales; por lo que las familias, tienen alguna posibilidad de obtener apoyo a través de los programas que impulsan los gobiernos, tanto municipales, estatales y el federal; el segundo grupo. lo tiene más complicado.

Los estudios sobre el colectivo de las personas en situación de calle, compuesto mayormente por hombres, han indagado las causas, condiciones de vida y percepción sobre la pobreza (Ceirano, 2000; Vasilachis, 2012; Groisman y Sconfienza, 2013; Serrano y Zurdo, 2013), rescatando una cantidad de elementos a tener en cuenta para analizar las trayectorias vitales de las personas que la confrontan y el concepto de movilidad social.

En este sentido, el siguiente trabajo tiene por objetivo identificar el significado de la responsabilidad como elemento de la identidad masculina configurada en los contextos de pobreza, desde la mirada retrospectiva de los hombres en situación de calle en Hermosillo, Sonora (México). 


\section{Pobreza, familia y desarrollo social}

Ser catalogada como una persona pobre implica tener una o más carencias sociales sin cubrir, mientras que tener tres o más necesidades significa vivir en contextos de pobreza extrema (CONEVAL, 2018). La pobreza multifactorial, implica que estar en esta situación no sólo es causa de no contar con un ingreso económico que cubra las necesidades básicas de la persona y de la unidad doméstica, sino que actualmente este fenómeno se mide por otros indicadores de bienestar económico y derechos sociales: Educación, salud, seguridad social, alimentación, vivienda y servicios de ésta.

Estas variables son el eje central del bienestar mínimo. Añadiendo el ingreso se obtiene el Índice de Pobreza Multidimensional, propuesto por la Comisión Económica para América Latina y el Caribe (CEPAL, 2014), que aporta "una perspectiva más plural y compleja del bienestar y su carencia, la pobreza" (Ponce, 2018, p.109). Aún en la Academia y entre las comisiones para el desarrollo social de los distintos países y organismos internacionales hay un debate abierto sobre los indicadores, vías de medición y validez de las estrategias de desarrollo humano, exponiendo lo complejo del fenómeno y la cantidad de variables que transversalizan esta situación.

De acuerdo con Sorzano, Rocha y Acosta (2021): "La pobreza está relacionada con las condiciones de vida que vulneran la dignidad, los derechos y las libertades" (p.69), de las personas, que tienen limitaciones para acceder o carecen de recursos, que les permita poder satisfacer sus necesidades básicas (Anaya, Buelvas y Romero, 2020). En ese sentido, no sólo se asocia con la escasez, sino que en el entramado de connotaciones, significados (Spicker, Álvarez y Gordon, 2009), dinámicas relacionales y estructuras culturales que subyacen a este problema, se entrelazan la exclusión social, el trabajo infantil, la marginación, la violencia, la decohesión social y la desigualdad de género, entre otros aspectos.

En el 2016 se contabilizaron 9.4 millones de personas en situación de pobreza extrema en México (CONEVAL, 2018). Los planes y programas destinados a mejorar la calidad de vida de las poblaciones a través del desarrollo social, se centran en las familias como eje de la intervención y la asistencia.

La familia se entiende como la unidad básica de satisfacción de necesidades primarias, sociales, de afecto, reconocimiento, protección y de control social (Delfín-Ruiz, Cano-Guzmán y Peña-Valencia, 2020). Ésta ha fungido como el vínculo primario de unión y socialización y conforma las bases para las relaciones intra-hogar, siendo fundamental para la creación de lazos de ayuda mutua y sustento en contextos de pobreza, a partir de intercambios, cooperación y solidaridad (Tuirán, 2001; Terranova, et al., 2019; Acosta, et al., 2019). La apuesta, por lo tanto, de la Administración pública para el bienestar de las familias con menos recursos y servicios, está encaminada hacia las y los jefes de familia desde una mirada práctica al aprovechamiento grupal de los recursos invertidos.

$\mathrm{Si}$ bien es cierto que hay programas de desarrollo social en México, aún se cuestiona su eficacia (Banegas-González y Mora-Salas, 2012; Muñoz, Marcelino-Aranda y BaldazoMolotla, 2019). Ante la marcada desigualdad, para las personas que nacen en contextos de pobreza, una de las estrategias por excelencia, desde hace más de medio siglo, ha sido la migración hacia los países del norte (geográfica y simbólicamente hablando), particularmente a los Estados Unidos de América (EUA).

\section{Migración, masculinidad y pobreza extrema}

Subirse al tren de la migración, aún a principios del siglo XXI, era una opción muy válida para los hombres jóvenes que empezaban a considerar formar una familia, pero que por las circunstancias económicas del lugar de origen no tenían acceso a la educación ni al desarrollo laboral. Los hombres fueron los 
que tomaron el protagonismo en estos viajes, a partir de la función de proveedores del sustento familiar que los roles de género tradicionales les asignaban. Siguiendo a Gilmore (1990), la masculinidad se dibuja desde el esquema de las tres "p": Protección, provisión y potencial.

Las masculinidades, son constructos socio-culturales, conformados por distintos elementos de caracterización, que delinean perfiles diferenciados según la cultura, los espacios geográficos y los estratos sociales, confirmando lo complejo de la comprensión de los roles de género y sus dinámicas relacionales en la cotidianidad (Montesinos, 2007; Téllez y Verdú, 2011). Los hombres jóvenes (muchos de ellos adolescentes aún) conformaban su masculinidad a través de esta responsabilidad, que además permitía no sólo aceptar el valor y la valentía que tenían, a ojos de las mujeres de la comunidad, sino amarrar esta opción como la vía más viable para generar ingresos, que después le permitiesen conformar su propio hogar (Hernández-Hernández, 2014).

En la actualidad, el flujo migratorio ha decrecido debido a los cambios en la seguridad fronteriza, al aumento de la violencia y a la situación político-económica del país receptor. La percepción sobre las oportunidades brindadas por los EUA está cambiando; los relatos que llegan desde el "otro lado" no son tan halagüeños para los millones de personas que intentan forjarse un futuro en dólares. No todas las historias de migración tienen un final triunfal y eso lo conoce de primera mano la población mexicana deportada, alrededor de 3.5 millones de personas entre 1998 y 2014 (Calva y Alarcón, 2018).

Los hombres que no alcanzan la meta establecida, por un sentimiento de "haber fallado" que les impide sentirse orgullosos, no regresan al hogar de origen. Es en ese contexto que buscan otros trabajos (formales o informales) o nuevos intentos de cruzar la frontera como las únicas opciones de desarrollo, y manteniendo un distanciamiento físico, territorial, comunicativo y emocional, con la familia, que configura idealizaciones de las condiciones vividas por ambas partes (Pedone, 2006).
Las dificultades económicas, sumadas a encontrarse en lugares extraños, sin redes de apoyo y con obstáculos para obtener un trabajo, hacen que la calle ${ }^{(1)}$ sea la única opción para mantenerse en espera de un cambio de suerte. En el caso del norte de México, la frontera se dibuja simbólicamente como un elemento relevante para la comprensión del fenómeno de la pobreza extrema en su vertiente masculina.

\section{Metodología}

La investigación se desarrolló en la ciudad de Hermosillo, capital de Sonora (México), donde hay un notable estancamiento de personas en situación de calle, quienes subsisten gracias a las organizaciones sin ánimo de lucro privadas y a las estrategias por ellas implementadas cotidianamente. Al ser un estado fronterizo, la ciudad recoge a quienes son deportados/as o a quienes no han podido cruzar a los EUA, quedándose en busca de nuevas oportunidades para trabajar en los campos agrícolas o desplazarse a otras zonas fronterizas.

El estudio es de tipo descriptivo desde un método interpretativo del discurso (Sayago, 2014), a partir del enfoque cualitativo. La técnica seleccionada, fue la historia de vida por considerar que ésta rescata de manera única las experiencias contadas desde la autopercepción social, indagando en sus vidas cotidianas para extraer los significados de la pobreza (Lewis, 1989; Narayan, 2000; Iglesias, 2013; Adler, 2016; Frausto, 2016; Romero, 2019).

Tras la identificación del centro que acoge a las personas en situación de calle, se realizaron varias visitas para conocer el lugar, las personas que acudían, los servicios prestados, la organización y el funcionamiento de éste. La persona responsable del centro, fue quien amablemente ayudó a contactar con los hombres que participaron en esta investigación; por lo tanto, la muestra fue por conveniencia.

La elaboración de los cuatro relatos de vida, fue posible por la realización de entrevistas semi-estructuradas, que permitieron 
dirigir la recogida de información en base a las categorías, desde las cuales se había planteado el proyecto: Recuerdos de niñez y juventud, causas de pobreza, consecuencias, educación, ámbito laboral, familia, relaciones sentimentales, migración, condiciones actuales y expectativas. Lo delicado del tema pesó en la salvaguarda de un espacio en las entrevistas, que no fuera sólo de grabación de relatos de recuerdos de los participantes, sino que creara una apropiación significativa de ese "contar lo mío", desembocando en una reflexión intrapersonal (Cornejo, Mendoza y Rojas, 2008).

Las entrevistas se desarrollaron en el Centro de Ayuda Humanitaria Casa Amiga(2), previo consentimiento de cada participante, siendo grabadas todas ellas en soporte digital. Tras la transcripción de éstas, se dio comienzo a la etapa de la elaboración de las historias de vida, desde las cuales se retomaron aspectos analíticos que permitieron el desglose de los significados de pobreza y la comprensión de las condiciones de vida en contextos de precariedad a partir de nuevos elementos.

\section{Historias de vida}

Los cuatro protagonistas de este artículo son Alfredo, Francisco, Alejandro y Celso (nombres no reales). A continuación, se presenta una breve reseña de sus historias de vida.

Alfredo, tiene 64 años y proviene de Tapachula (Chiapas). Estudió hasta el nivel de secundaria y decidió migrar siendo joven a diferentes estados de la república mexicana. Después migró a los EUA, donde vivió varios años. Es soltero y no ha tenido descendencia. Desde su última deportación, hace más de quince años, vive en Hermosillo, trabajando en la venta del periódico, actividad informal que le ayuda a cubrir algunas necesidades básicas. Piensa regresar a su tierra de origen sólo de visita, porque él ya se considera "naranjero"(3) y quiere quedarse en Sonora.

Celso, de 59 años, es divorciado y tiene seis hijos/as. Es originario de una comunidad indígena, Santa Rosa, en Toluca (Estado de México). Sólo estudió hasta el grado de primaria. Se casó muy joven. Desde pequeño migró junto a sus padres, quienes trabajaban en la recogida de la fruta en los campos agrícolas del norte del país. Cruzó en dos ocasiones la frontera y estuvo trabajando en EUA hasta que lo deportaron. Siempre ha estado migrando para proveer el sustento de su prole. Hace unos meses sufrió un accidente que le imposibilitó seguir siendo velador de una obra en construcción. En la actualidad, vende periódicos en un parque céntrico de la capital.

Francisco, es de Ciudad Obregón (Sonora) y estudió hasta la secundaria. De joven quiso irse a los EUA a probar suerte; aunque lo que le esperó allí fue el contacto con las drogas. Tras ser deportado, y vivir un suceso impactante familiar en su vida, decidió regresar a la frontera norte, donde tras vagar un tiempo sin rumbo decidió asentarse en Hermosillo. Hace más de un año ha cambiado su estilo de vida. Abandonó el consumo de drogas y actualmente trabaja en un restaurante. Tiene 51 años y nunca se casó ni tuvo hijos/as.

Alejandro, es el más joven, con 49 años, y acaba de terminar la secundaria (a través de un programa gratuito para adultos) en Sonora. Nació en Veracruz, siendo abandonado por su madre y criado por una tía. Salió rumbo a Tijuana cuando era adolescente para probar suerte en el trabajo y aunque intentó varias veces cruzar la frontera, decidió quedarse en Hermosillo, donde de vez en cuando le salen trabajos que le ofrecen la oportunidad de rentar una casa. Sin embargo, en las rachas malas (como la actual) vive de lo que la venta de dulces o el lavado de carros le dejan. Acude habitualmente al albergue. Es soltero y sin descendencia.

\section{Resultados y discusión}

\subsection{Responsabilidad y libertad}

La migración, es un fenómeno que para la población de escasos recursos se conforma 
como una vía de oportunidad laboral y de crecimiento económico, que se traspasa de generación a generación. Éste es el caso de Celso, quien vivió la migración desde niño junto a sus padres, quienes viajaban a Sonora o Baja California a trabajar en los campos agrícolas por temporadas. Su familia fue numerosa: Tuvo catorce hermanos. Ante el panorama desolador de la economía rural de Toluca siguió implementando esta estrategia económica para formar una familia. Tanto es así, que su exesposa también fue con él al norte para conseguir trabajo de ayudante de cocina, en los campos donde Celso se desempeñaba como jornalero. Cuando llegó el momento de cruzar al otro lado, Celso fue solo, puesto que la familia había crecido y lo más apropiado era inspeccionar primeramente las condiciones del lugar de destino sin colocar en peligro a ésta.

También la migración por motivos económicos, se puede configurar como una opción de conocer nuevos lugares, de vivir experiencias y de crecimiento personal, a modo de aventura; sobre todo para los más jóvenes. Por lo tanto, esta responsabilidad migratoria se asume también como parte de su libre decisión de vivir bajo un estilo que les provee de cierta libertad para y con su propia persona. Así lo significó Alfredo. Chiapas, uno de los estados con mayores índices de pobreza de todo el país, es una región expulsora de migrantes hacia el resto del territorio nacional, particularmente al centro y norte mexicano.

Alfredo, se crio en una hacienda cafetera de Tapachula y el llamado a la aventura y a vivencias interesantes fue lo que le hizo decidirse por abandonar su tierra natal rumbo al norte. Su padre le transmitió ese entusiasmo: "Yo soy aventurero desde mi juventud, mi papá me enseñó a la aventura. Él fue aventurero y me dijo [que algún día] lo [iba] a necesitar". En EUA vivió en diferentes estados (Alabama, Carolina del Norte y Texas), trabajando en la recogida de distintos frutos. En su segunda deportación, decidió no volver a cruzar la frontera más: "Me dijeron los gringos que no lo hiciera, porque si no me iban a castigar y por eso yo respeto [...] lo ajeno. Yo respeto su muro $[\ldots]$, es prohibido para mí".
Salir de Veracruz, fue una elección que tomó Alejandro para probar suerte con un amigo en los campos agrícolas del norte del país. Su primer destino fue Tijuana, Baja California. Tras cuatro intentos por cruzar la frontera, Alejandro desistió y decidió fluir con su suerte y quedarse en Sonora, donde ha tenido varios trabajos de construcción. Actualmente, el vagar y no colocar demasiada atención a las ofertas laborales le han hecho que no tenga un empleo, teniendo que asistir al albergue Casa Amiga, con el fin de proveerse de un techo y comida.

El caso de Francisco, es el más singular. Con la familia que cuenta son tres hermanas (Ana, Beatriz y Leticia) y sus sobrinos. Su hermano ya falleció. La decisión de no estudiar y de migrar la tomó en su adolescencia y ahora está trayendo sus más crueles consecuencias. Pasó catorce años sin regresar a Ciudad Obregón.
Partí de Obregón por problemas familiares y estuve en Nogales. Toda mi juventud he estado conviviendo con las drogas. Y para serles sincero, la situación de las drogas es lo que me impuso a andar en la calle porque no fui rechazado por mi familia. La misma forma de vivir con la droga [me llevó a tener] problemas conmigo mismo. (Francisco)

En ese sentido, Francisco por rachas, fue consiguiendo algunos trabajos que le permitían salir a flote de situaciones de desesperación y de la calle, pero que retornaban al consumo de drogas.

\subsection{Des-vínculo con la familia}

Ante la escasez, la opción de migrar tentó a los cuatro hombres. Por un lado, la responsabilidad de proveer a una familia a punto de conformarse (Celso) o de no ser una carga para la familia de origen (Alfredo, Alejandro y Francisco) y, por otro lado, la conformación de su identidad masculina (Hernández-Hernández, 2014), basada en la responsabilidad varonil, hizo que esta decisión 
fuera fácil y rápida.

$\mathrm{La}$ experiencia de viajar, aunque el camino esté lleno de peligros, es una vivencia enriquecedora que todos ellos han expresado, haciendo hincapié en los lugares que han conocido y en los aprendizajes que les han dejado las personas con quienes se han encontrado a lo largo de su trayecto y sus acciones. La contraparte se dibuja a través de los obstáculos, como las deportaciones, experiencias negativas y miedos, así como del distanciamiento con la familia, la comunidad y con lo conocido/seguro.

El alejamiento con la familia de origen, está representado en tres de los casos (Alfredo, Francisco y Alejandro) y se relaciona con la libertad brindada a éstos, como varones y su escaso contacto emocional (Echeverría, 2013) y como un regalo por la responsabilidad asumida al migrar. En sus narrativas hay una justificación de ruptura, que se torna más en una estrategia individual para sobrellevar la nostalgia del terruño que en una explicación de la distancia. Si bien es cierto que se menciona la distancia física, ésta es más emocional que territorial.

Alfredo y Alejandro, no mantienen contacto con su familia ni con su pueblo natal. Alfredo, sigue teniendo en un hueco de su corazón a Chiapas, tanto que él sigue invitando a que vaya la gente porque "allí tienen su casa". Comenta, no con gesto de preocupación o tristeza, que ya las relaciones se rompieron con su familia, porque ellos tienen hechas sus propias vidas. Le quedan vivos cuatro hermanos: Jesús, Alicia, Rosa María y José. Comenta acerca de ellos:

Ya tienen su hogar, ya tienen hijos (...). Ya hicieron sus vidas y yo ya hago la mía. Estuve [en Chiapas] una temporada, aunque sin amor porque dejé de ver muchos años a mi familia. Ya no había amor, no había amor en la casa, ni el amor de los padres, de los hermanos, de los vecinos ni de los amigos. Lo ven a uno con extrañeza. Así que decidí volver a EUA.

Por su parte, Alejandro, que vivió su infancia y parte de su juventud con una tía, debido a que su padre falleció antes de que él naciera y su madre le abandonó, dice no tener nada que atender en Veracruz. Él siente que debe seguir con su camino. A sus cuatro medio hermanos no los siente de la familia, porque, según él, nunca se han preocupado por él. "Imagino que allí deben de estar todos. Me alejé de la familia hasta la fecha. No estuve mucho con mi familia. De hecho, llevo casi 12 años que no sé de ellos".

Tal fue el alejamiento que la familia de Francisco pensó que había fallecido porque llevaba años desaparecido. Llevaban años sin saber de él, hasta que un día se presentó en su hogar en Ciudad Obregón y todos quedaron sorprendidos. Respecto a esto él dice lo siguiente: "No me sentí mal, porque ya uno prácticamente [se había deslindado de toda la familia]". Francisco, hace poco que comenzó una racha de paz interior, tranquilidad y mucho esfuerzo para combatir los vicios y alcanzar una estabilidad emocional así como económica. Visitó a su familia en el sur de Sonora y se comprometió consigo mismo a "echarle muchas ganas" para superar la situación de pobreza que había estado viviendo.

Para Celso, la familia se subdivide en dos: La de origen (con su madre y hermanas) y la propia (con sus hijos/as y nietos/as). Tras años fuera del hogar, aunque existiera una justificación de desarrollo familiar, la distancia entre su esposa y él terminó rompiendo la relación sentimental entre ambos, llegando al divorcio, lo cual quebró uno de los lazos fuertes que Celso tenía con su hogar. Las relaciones y las cargas familiares de quienes se quedan, se vuelven esenciales después de años de enfrentar la lejanía del proveedor principal de la familia, construyendo nuevas alianzas, dinámicas y lealtades (López y Loaiza, 2009).

Celso, a pesar de echar de menos a su madre, no sabe cuándo podrá volver a Santa Rosa. Ya fallecieron algunas de sus hermanas. Ante esto dice: "Ahora no sé, a lo mejor ya falleció alguien más. Antes hablaba más con la familia, pero ahorita ya no porque no tengo teléfono; lo tuve que vender para poder solventar esto del accidente". El sentir que ya no es útil no le deja ver más escenarios. En las fiestas navideñas Celso pensaba regresar, 
pero un fatal accidente le dejó sin recursos económicos y con una pierna escayolada. A partir de ese momento, dejó de trabajar de velador en varias construcciones, empezar a acudir al albergue y vender el periódico en un parque cercano, puesto que necesita descanso y medicinas.

A excepción de Francisco, ninguno tiene contacto con su familia. La vergüenza sentida de no haber podido alcanzar la meta, y verse en la situación de pobreza extrema, construye un "muro" simbólico, para no pedir ayuda, que se torna a un "muro" real entre la familia y ellos, dañando las redes de confianza. Al respecto, Bermúdez (2016) sostiene que:

Las estructuras socioculturales del género son precisamente elementos que funcionan de manera tanto endógena como exógena en la realidad de estas personas, y serán precisamente las estructuras dominantes de los discursos del género las que limiten su posibilidad de agencia, y por tanto su capacidad de elegir su modo de vida. (p.70)

La aceptación del presente, desarrolla una adaptación a su situación que los hace tener expectativas no reales, basadas en conseguir una pensión, rentar una "casita" y estar tranquilos y felices, pero sí optimistas. La ruptura o alejamiento con la familia, hace que cada persona vuelva a construir y resignificar la idea de "hogar". Estos cuatro hombres consideran que el albergue Casa Amiga es ahora su hogar.

\subsection{Situación actual: Tiempo de reflexión}

La posición actual, basada en un contexto de precariedad y de escasos apoyos para el desarrollo, lejos del lugar de origen y con las redes de confianza rotas o heridas, regala el espacio para una reflexión que está cargada de expectativas, culpas y añoranzas, donde el papel de la masculinidad juega desde el orgullo, pero también desde la madurez de ver la esperanza. La falta de contacto con su familia, hace que Chiapas vaya quedando poco a poco más en el recuerdo nostálgico de
Alfredo que como una opción de apoyo. Al respecto, manifiesta:

Son mi sangre y sí los extraño. De vez en cuando me vienen a la mente sus imágenes, pero yo los respeto. Quizá algún día haya oportunidad de ir a Chiapas otra vez de visita. Sólo de visita porque yo ya soy sonorense, ya soy naranjero.

Celso, no tiene intención de volver a su hogar. "No quisiera irme para allá porque no me siento bien pidiendo. Al revés, me siento con obligación de darles todavía. Así me enseñaron y así me educaron". Dice que no quiere dar castigo ni trabajo a su familia. Ante la falta de dinero, la posición de utilidad como hombre se pierde. En su discurso, dice que no quiere ir con sus hijas tampoco porque ellas ya tienen su vida hecha y sólo les daría más trabajo. "Tienen todo y no necesitan nada de mí".

Incluso, esta norma de valor masculino sigue rigiendo su vida actualmente. Las directrices de lo que "debe de ser" un hombre, están interiorizadas desde que son niños y se basa en la educación de género (o más bien, en la no educación de género) donde los hombres padres de familia, han medido su valía a través de su rol proveedor (Amuchástegui y Szasz, 2007). Celso, comenta que actualmente no tiene pareja, pero no pierde la esperanza, una vez que se recupere económicamente, de encontrarse con una compañera. Pero esto sólo ocurrirá cuando vuelva a trabajar. Asimismo, Alfredo recuerda que "sin dinero no hay amor". En estos significados, se observa la educación recibida por los hombres, quienes definen el amor hacia ellos a partir de su esfuerzo y éxito. En los discursos, se resignifica la concepción de utilidad masculina como uno de los valores agregados a ser hombre (Tello, 2016).

Por su parte, Francisco, gracias al consejo de un buen amigo del albergue sobre recuperar el contacto con los seres queridos, ha reanudado la comunicación con su familia, lo cual es un paso muy importante para sanar y regenerar el sentir respecto a este elemento en las vidas de cada persona. "Actualmente tengo comunicación con mi familia. No hablo precisamente a diario, pero sí una vez por semana. Yo llamo a mis hermanas o ellas a 
mí’. El cambio en su situación, le está llenando de esperanza y motivación para la estabilidad.

Para Alejandro, los lazos familiares se rompieron hace mucho tiempo. Aunque hay un perdón hacia su madre, por abandonarle y un agradecimiento eterno hacia su tía, por haberle cuidado, el distanciamiento ha hecho que el camino sea su hogar presente. "Quería ir en fin de año porque en las Navidades se acuerda uno de la familia. Pero cualquier día sería bueno para volver a ver caras cercanas y sentirse en el verdadero hogar".

Recapitulando los hallazgos de este estudio en el norte de México (véase Figura I), se considera que hay una relación directa entre la vergüenza de los hombres migrantes, sentida al perder la oportunidad de cruzar al otro lado o a partir del "fracaso" por ser deportados, y la situación de pobreza extrema a la que llegan. Este sentimiento, les impide simbólicamente regresar a su comunidad de origen y pedir ayuda, años o décadas después de haberse ido.

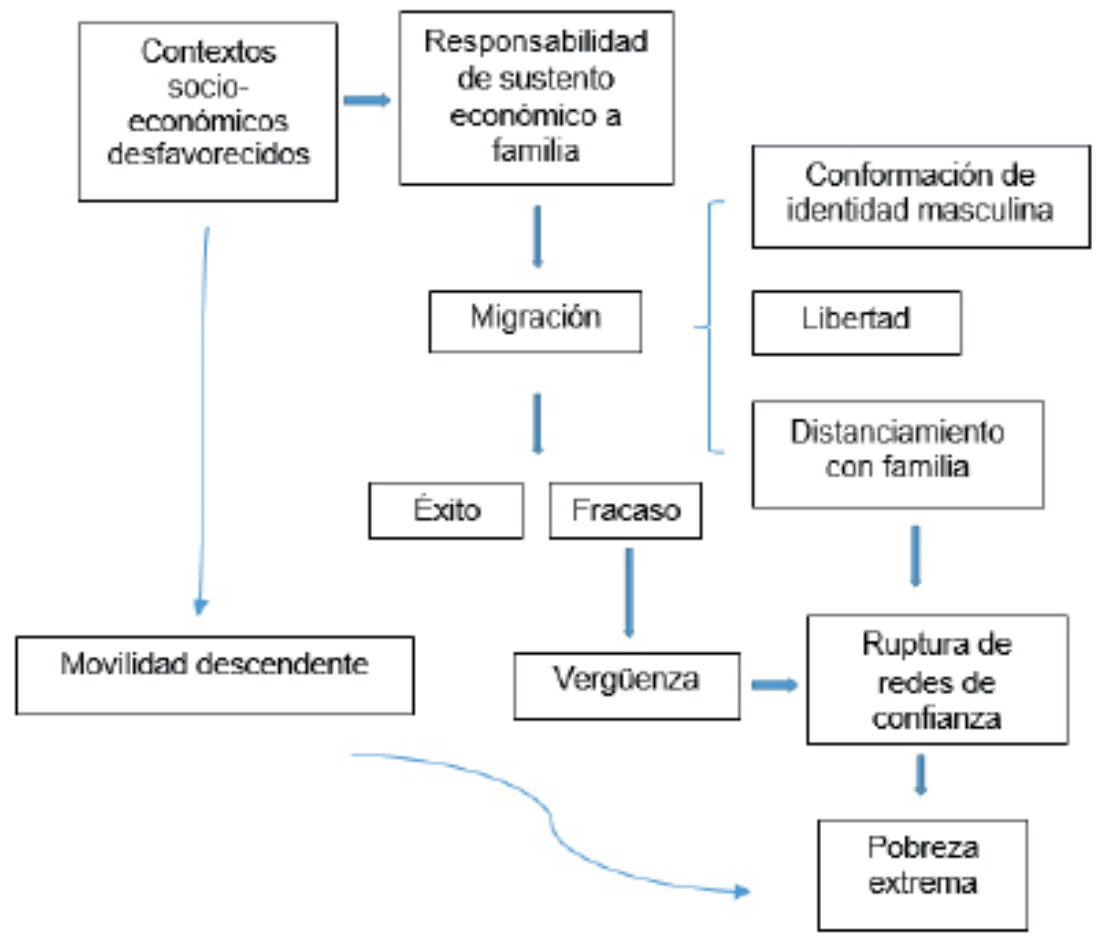

Fuente: Elaboración propia, 2020.

Figura I: Responsabilidad, vergüenza y pobreza extrema 
Esta construcción emocional y de toma de decisiones, proveniente de la educación en valores y roles de género otorgada tradicionalmente al varón mexicano (Kimmel, 2008; Segal, 2008; Machillot, 2013), es más fuerte que la utilidad de las redes de apoyo familiares en situaciones de precariedad. Se convirtieron en hombres responsables, que aceptaron y eligieron la migración desde tres ejes: a) Como una obligación indirecta, bajo la cual se reconocía su valor; b) como una puerta para la conformación y consolidación de su identidad masculina; y, c) como un espacio de libertad (manejado como una recompensa por el esfuerzo de hacerse cargo de la protección de la familia).

\section{Conclusiones}

La conformación de la identidad masculina en contextos de pobreza, está tildada por la función de proveer económicamente a la unidad doméstica, con el fin de sostener o ayudar al mantenimiento del hogar, incluso desde edades tempranas (trabajo infantil). Desde la idea del trabajo como perfilador del valor masculino, la migración cobra importancia hacia la solvencia económica, la seguridad y el poder. Ser migrante conlleva responsabilidad y libertad. Ambas dibujan un distanciamiento, que implica idealización sobre la situación de sus padres, hermanos o hijos migrantes, y unas relaciones familiares desgastadas por el tiempo, el espacio y por la falta de palabras, quedando las redes de confianza y apoyo débiles.

Cuando no se cumplen las expectativas proyectadas ante la migración, se incorpora erróneamente el significado de "fracaso", que lleva directamente a un sentimiento de vergüenza, puesto que el rol esperado del varón no se ha cumplido. En esta etapa, se construye un segundo distanciamiento como una estrategia para alejarse del espacio de culpa y para "seguir adelante", haciéndose responsables de sus vidas y de las consecuencias de sus acciones.

Se resalta la necesidad de incluir la educación de género (formal y no formal) con la finalidad de erradicar las barreras creadas por el patriarcado ante los posicionamientos tradicionales del deber ser mujer y del deber ser hombre. Ésta debe atender las emociones, la autopercepción y los nuevos espacios de masculinidad, donde la familia resurja desde posicionamientos más flexibles en connotaciones, prácticas y sentires.

Atendiendo este aporte, se considera esencial integrar la categoría del género, desde las masculinidades, en los estudios de pobreza, con el fin de comprender las dinámicas de identidad, hegemonía y responsabilidad, que pesan sobre este grupo poblacional en situación de calle, puesto que aún el género no se ha retomado como un elemento relevante del fenómeno en pro de acciones de intervención social.

En una sociedad donde "la pobreza, la desigualdad y la creciente inseguridad laboral han ido acompañadas de la fragmentación de la protección social y de la asistencia en detrimento de la cobertura universal de los derechos" (Dautrey, 2013, p.26), es necesario más que nunca que la política social dialogue con las personas en contextos de vulnerabilidad para encontrar un punto común de intervención social. Una propuesta metodológica desde la Academia, dirigida hacia las y los creadores de política pública, es el rescate de las historias de vida como técnica de investigación, la cual proporciona información en significados, emociones, prácticas así como percepciones sociales, además de proveer de espacios de desahogo y reflexión a las personas que son partícipes de éstas.

Lejos de conformar un perfil del hombre en situación de pobreza extrema, este artículo identifica algunos aspectos que pudieran ser comunes al varón mexicano migrante, que actualmente está varado en la frontera norte tras haber sido deportado. Con este estudio no se pretende generalizar, sino presentar elementos de análisis que pudieran coadyuvar a la comprensión del fenómeno (no nuevo) de la pobreza extrema, incluir categorías de revisión en los estudios de movilidad socioeconómica y abrir líneas de investigación ante 
el panorama (floreciente) de estancamiento de hombres adultos (mayores) y exmigrantes que están en las calles de México en espera del rescate de las políticas sociales.

\section{Notas}

${ }^{1}$ Uno de los escenarios de mayor vulnerabilidad de la pobreza extrema se delimita en la situación de calle, por la inseguridad expuesta (física, emocional, alimentaria, de higiene, entre otras) y por las consecuencias materiales, psicológicas y de aspecto que desencadena.

${ }^{2}$ Esta instancia brinda un alojamiento nocturno y una cena caliente, además de acceso a duchas, baños y al servicio de lavadora. El costo por acceder al recinto a dormir es de veinte pesos por día. El albergue abre todos los días a las cinco de la tarde para que pueda entrar la población, previo pago y revisión de cumplir los requisitos de acceso (no haber consumido alcohol ni drogas duras). La salida de la población se realiza a las cinco de la mañana, hora en la que las y los asistentes salen del mismo para comenzar un día más de vida.

3 Los Naranjeros, son el equipo local hermosillense de béisbol profesional que juega en la Liga mexicana del Pacífico.

\section{Referencias bibliográficas}

Acosta, A., Molina, C. A., Andino, T. S., y Rodríguez, V. E. (2019). Sistema familiar y continuidad de las empresas familiares. Revista de Ciencias Sociales (Ve), XXV(4), 265-275.

Adler, L. (2016). Cómo sobreviven los marginados. Siglo XXI.

Amuchástegui, A., y Szasz, I. (Coords.) (2007). Sucede que me canso de ser hombre... Relatos y reflexiones sobre hombres y masculinidades en México. El Colegio de México.
Anaya, A. R., Buelvas, J. A., y Romero, Y. (2020). Pobreza e inclusión financiera en el municipio de Montería, Colombia. Revista de Ciencias Sociales (Ve), XXVI(1), 128-143. http://dx.doi. org/10.31876/rcs.v26i1.31315

Banegas-González, I., y Mora-Salas, M. (2012). Transferencias condicionadas y reducción de la pobreza en México: Entre lo real y lo imaginado. European Review of Latin American and Caribbean Studies, (93), 41-60. https://doi.org/10.18352/erlacs.8363

Bermúdez, B. A. (2016). Masculinidades, justicia social y personas en situación de calle: caminos en constante movimiento. En M. Fernández (Coord.), Miradas multidisciplinarias en torno a la masculinidad: Desafios para la impartición de justicia (pp. 151-171). Suprema Corte de Justicia de la Nación.

Calva, L. E., y Alarcón, R. (2018). Migrantes mexicanos deportados y sus planes para reingresar a Estados Unidos al inicio del gobierno de Donald Trump. Revista Mexicana de Ciencias Politicas y Sociales, LXIII(233), 43-68. $\quad$ http://dx.doi.org/10.22201/ fcpys.2448492xe.2018.233.62603

Cámara de Diputados del H. Congreso de la Nación (2018). Ley General de Desarrollo Social. Últimas reformas publicadas DOF 25-06-2018. http:// www.diputados.gob.mx/LeyesBiblio/ pdf/264_250618.pdf

Ceirano, V. (2000). Las representaciones sociales de la pobreza. Cinta de Moebio, (9), 337-350.

Comisión Económica para América Latina y el Caribe - CEPAL (2014). Panorama Social de América Latina 2014. CEPAL. https://www.cepal.org/es/ publicaciones/37626-panoramasocial-america-latina-2014 
Masculinidad, migración y pobreza extrema: Mirada retrospectiva de exmigrantes en Hermosillo, Sonora-México

Consejo Nacional de Evaluación de la Política de Desarrollo Social - CONEVAL (2017). Informe de evaluación de la política de desarrollo social 2016. CONEVAL. https://bit.ly/3ahWb43

Consejo Nacional de Evaluación de la Política de Desarrollo Social - CONEVAL (2018). Informe de evaluación de la politica de desarrollo social 2018. CONEVAL. https://bit.ly/2QcMwFk

Cornejo, M., Mendoza, M., y Rojas, R. C. (2008). La investigación con relatos de vida: Pistas y opciones del diseño metodológico. Psykhe, 17(1), 29-39. http://dx.doi.org/10.4067/S071822282008000100004

Dautrey, P. (2013). Precariedad de la sociedad, segmentación de la política social: el caso de México. European Review of Latin American and Caribbean Studies, (94), 25-42. https://doi. org/10.18352/erlacs.8391

Delfín-Ruiz, C., Cano-Guzmán, R., y PeñaValencia, E. J. (2020). Funcionalidad familiar como política de asistencia social en México. Revista de Ciencias Sociales (Ve), XXVI(2), 43-55. https:// doi.org/10.31876/rcs.v26i2.32421

Echeverría, G. (2013). Vulnerabilidad en los varones mexicanos: Fisuras y aperturas en las subjetivaciones masculinas. En J. C. Ramírez y J. C. Cervantes (Coords.), Los hombres en México: Veredas recorridas y por andar (pp. 37-49). Universidad de Guadalajara, CUCEA y AMEGH, A.C.

Frausto, S. (Coord.) (2016). Los 12 mexicanos más pobres. El lado $B$ de la lista de millonarios. Editorial Planeta.

Gilmore, D. D. (1990). Manhood in the making: Cultural concepts of masculinity. Yale University Press.

Groisman, F., y Sconfienza, M. E. (2013). Indigentes urbanos: Entre la estigmatización y la exclusión en la ciudad de Buenos Aires. Revista de Estudios Sociales, (47), 92-106.

Hernández, M. (2010). El estudio de la pobreza y la exclusión social. Aproximaciones cuantitativas y cualitativas. Revista Interuniversitaria de Formación del Profesorado, 24(3), 25-46.

Hernández-Hernández， O. M. (2014). Menores mexicanos repatriados de Estados Unidos y configuración de la masculinidad. En O. M. HernándezHernández y M. E. Ramos (Coord.), Migrantes allá y acá. Mujeres $y$ hombres en Estados Unidos y el noreste de México (pp. 65-86). Universidad Autónoma de Nuevo León y Gobierno del Estado de Tamaulipas.

Iglesias, N. (2013). La flor más bella de la maquiladora. El Colegio de la Frontera Norte.

Kimmel, M. (2008). Los estudios de la masculinidad: una introducción. En A. Carabí y J. M. Armengol (Eds.), La masculinidad a debate (pp. 15-32). Icaria.

Lewis, O. (1989). Antropología de la pobreza. Cinco familias. Fondo de Cultura Económica.

López, L. M., y Loaiza, M. O. (2009). Padres o madres migrantes internacionales y su familia: Oportunidades y nuevos desafíos. Revista Latinoamericana de Ciencias Sociales, Niñez y Juventud, 7(2), 837-860.

Machillot, D. (2013). El estudio de los estereotipos masculinos mexicanos en las Ciencias Humanas y Sociales: Un recorrido crítico-histórico. En J. C. Ramírez y J. C. Cervantes (Coords.), Los hombres en México: Veredas recorridas y por andar (pp. 17-35). Universidad de Guadalajara, CUCEA y AMEGH, A.C.

Montesinos, R. (2007). Ensayando sobre nuevas tipologías de masculinidad. En 
M. L. Jiménez y O. Tena (Coords.), Reflexiones sobre masculinidades y empleo (pp. 181-204). Centro Regional de Investigaciones Multidisciplinares UNAM.

Muñoz, D., Marcelino-Aranda, M., y BaldazoMolotla, F. (2019). Disminución de la pobreza en México: análisis del programa Prospera. En M. I. García y M. C. Martínez (Coords.), La gobernanza en las finanzas públicas y privadas en México (pp. 117-136). Ediciones Colofón.

Narayan, D. (2000). La voz de los pobres. ¿Hay alguien que nos escuche? Banco de Reconstrucción y Fomento/Banco Mundial y Mundi-Prensa.

Pedone, C. (2006). Los cambios familiares y educativos en los actuales contextos migratorios ecuatorianos: Una perspectiva transatlántica. Athenea Digital, (10), 154-171. https://doi. org/10.5565/rev/athenead/v1n10.298

Ponce, M. G. (2018). Medición de pobreza multidimensional de la iniciativa en pobreza y desarrollo humano. Revista de Ciencias Sociales (Ve), XXIV(4), 98-113.

Romero, V. (2019). Vivir bajo el cielo. Pobreza $y$ masculinidad en las fronteras. Editorial Fontamara y Universidad de Sonora.

Sayago, S. (2014). El análisis del discurso como técnica de investigación cualitativa y cuantitativa en las ciencias sociales. Cinta de Moebio, (49), 1-10. http://dx.doi.org/10.4067/ $\underline{\text { S0717-554X2014000100001 }}$

Segal, L. (2008). Los hombres tras el feminismo. ¿Qué queda por decir? En A. Carabí y J. M. Armengol (Eds.), La masculinidad a debate (pp. 155-176). Icaria.

Serrano, A., y Zurdo, Á. (2013). Representaciones audiovisuales de las personas sin hogar: Entre la espectacularización de la exclusión social extrema y la culpabilización de las víctimas. Revista Española de Sociología, (20), 105-137.

Sorzano, D. M., Rocha, D., y Torres, A. (2021). Combate a la pobreza y percepciones de beneficiarios en la frontera sur de México. Revista de Ciencias Sociales (Ve), XXVII(1), 66-83.

Spicker, P., Álvarez, S., y Gordon, D. (2009). Pobreza: Un glosario internacional. CLACSO-CROP.

Téllez, A., y Verdú, M. D. (2011). El significado de la masculinidad para el análisis social. Revista Nuevas Tendencias en Antropología, (2), 80-103.

Tello, C. (2016). Las nuevas masculinidades. Un análisis con estudiantes de la Universidad Autónoma del Estado de Hidalgo. En M. A. Hernández y C. S. Gómez (Coords.), Masculinidades y violencia de género en instituciones educativas (pp. 153-172). Editorial Porrúa.

Terranova, A. E., Viteri, E. A., Medina, G. M., y Zoller, M. J. (2019). Desarrollo cognitivo y funcionalidad familiar de infantes en las comunidades urbanomarginales de Ecuador. Revista de Ciencias Sociales (Ve), XXV(E-1), 330-340.

Tuirán, R. (2001). Estructura familiar y trayectorias de vida en México. En C. Gomes (Comp.), Procesos sociales, población y familia: alternativas teóricas y empíricas en las investigaciones sobre la vida doméstica (pp. 20-66). FLACSO.

Vasilachis, I. (2012). Pobres, pobreza, identidad y representaciones sociales. Gedisa. 